\title{
WEB-BASED COMPUTER ASSISTED DESIGN UNTUK DIMENSI BANGUNAN TALANG DAN GORONG-GORONG
}

\section{(Web-Based Computer Assisted Design for the Dimensions of Gutter and Culvert Buildings)}

\author{
Jasmila $^{\left.1^{*}\right)}$, Ahmad Munir ${ }^{2)}$, dan Mahmud Achmad ${ }^{3)}$ \\ ${ }^{1)}$ Program Studi Teknik Pertanian, Universitas Hasanuddin, Makassar \\ ${ }^{2}$ Program Studi Teknik Pertanian, Universitas Hasanuddin, Makassar \\ ${ }^{3)}$ Program Studi Teknik Pertanian, Universitas Hasanuddin, Makassar \\ *) Email korespondensi: jasmilaaa18@gmail.com
}

\begin{abstract}
ABSTRAK
Salah satu aspek sarana dan prasana yang penting untuk pertanian adalah bangunan irigasi. Bangunan irigasi berfungsi untuk menyediakan aliran air pada areal persawahan. Pada bangunan irigasi terdapat berbagai jenis bangunan termasuk bangunan pelengkap. Secara umum proses perancangan bangunan irigasi terkhusus pada bangunan talang dan goronggorong masih dilakukan secara manual dimana membutuhkan analisis perhitungan dimensi dan perancangan yang rumit. Berdasarkan hal tersebut, didukung dengan kemajuan teknologi informasi (TI) maka dapat diterapkan sistem perancangan secara online melalui sistem website yaitu web based computer assisted design. Tujuan website ini yaitu dapat digunakan untuk membantu perhitungan secara umum atau perancangan bangunan irigasi dalam melakukan pekerjaan perhitungan dimensi bangunan pelengkap irigasi. Metode yang digunakan pada penelitian ini yaitu metode Web Development Life Cycle (WDLC) yang meliputi analisis kebutuhan, website planning, pengembangan web dan implementasi. Hasil penelitian menampilkan website yang terdiri dari beberapa menu yaitu menu home, konversi, kalkulator, referensi, bantuan dan tentang. Dari enam menu yang ada terdapat dua menu utama dan empat menu tambahan, yang menjadi menu utama yaitu menu konversi dan kalkulator. Pada menu konversi dapat digunakan untuk mengkonversi jenis satuan Panjang, kecepatan, dan volume sedangkan pada menu kalkulator terdapat kalkulator untuk perhitungan dimensi gorong-gorong dan talang yang terdiri dari luas penampang (A), jari-jari hidrolis (R), keliling basah (P) lebar saluran (b), kedalaman saluran (h). Dengan demikian para perancang dapat dengan mudah melakukan perencanaan dan perancangan bangunan yang ekonomis dengan memperhitungankan dimensi yang sesuai dengan perhitungan.
\end{abstract}

Kata Kunci: Bangunan irigasi, Bangunan pelengkap, Dimensi bangunan, website.

\section{PENDAHULUAN}

\section{Latar Belakang}

Irigasi menjadi faktor penting pada kegiatan pertanian. Irigasi di bangun untuk memenuhi kebutuhan mengairi areal persawahan. Jaringan irigasi yang di bangun umumnya berskala kecil dan bentuknya relatif sederhana sehingga diperlukan pengelolaan pada sistem jaringan irigasi.
Pengelolaan sumber daya air untuk lahan pertanian dapat dilakukan dengan pengembangan sistem jaringan irigasi. Sistem irigasi dibagi menjadi bangunan utama, saluran, sadap dan pelengkap. Bangunan pokok yang ada di dalam sistem tersebut merupakan bangunan pengatur dan pengukur jumlah air irigasi yang di perlukan oleh daerah layanan. 
Selain bangunan pokok terdapat bangunan-bangunan lain pada jaringan irigasi, salah satu bangunan yang terdapat dalam jaringan irigasi adalah bangunan pelengkap. Bangunan pelengkap irigasi dibuat untuk menjaga area pengairan terhadap kelebihan air yang bersumber dari sungai, danau atau waduk untuk keperluan irigasi pertanian. Bangunan pelengkap irigasi yang ada dalam sistem jaringan irigasi dapat berupa gorong-gorong, biangunan terjun, talang, sipon dan lain-lain

Perkembangan teknologi yang semakin pesat atau dikenal dengan era reformasi yang mana segala sesuatu sudah bersifat digital. Era ini didukung dengan teknologi informasi yang membantu dalam mempercepat atau peningkatan kesesuaian data, pada proses pencatatan dan pengolah data agar terbentuk sebuah informasi yang dapat disampaikan melalui online.

Dengan demikian komputer menjadi sangat penting diberbagai bidang yang menjadi faktor pendukung pada setiap aspek kehidupan. Semua bidang termasuk bidang pertanian menjadikan komputer sebagai kebutuhan utama dalam penyimpan dan pengolahan data. Komputer memegang peranan penting untuk membantu mengerjakan sesuatu pekerjaan. Dengan diciptakannya komputer kesalahan menjadi lebih kecil, proses pengolahan data menjadi lebih cepat, dan penyimpanan data dapat dengan jangka waktu lama dan berkapasitas lama.

Berdasarkan uaraian maka perlu dilakukan penelitian web-based computer assisted design untuk dimensi bangunan talang dan gorong-gorong yang dapat digunakan untuk mendesain dimensi dari bangunan talang dan gorong-gorong agar dapat mempermudah dalam pemberian informasi yang berkaitan dengan bangunan irigasi.

\section{Tujuan dan Kegunaan}

Tujuan dari penelitian ini yaitu untuk memudahkan dalam perencanaan dan perancangan bangunan talang dan goronggorong.
Kegunaan penelitian ini adalah memberi alternatif dalam membuat website yang lebih dekat pada perancangan bangunan talang dan gorong-gorong.

\section{METODE PENELITIAN}

\section{Alat}

Penelitian ini membutuhkan beberapa perangkat keras yaitu laptop, Flashdisk, CD disket serta kebutuhan perangkat lunak untuk menjalankan web yaitu software visual studio, apache Browser engine: Mozilla 5.0, Chrome 28.0.1469.0, perangkat lunak untuk implementasi dan pengujian sistem.

\section{Rancangan Sistem dan Implementasi}

Rancangan sistem yang dilakukan dalam penelitian ini yaitu berdasarkan metode Web Development Life Cycle (WDLC) yang meliputi tahapan sebagai berikut:

\section{Website planning}

Tahapan ini mencakup beberapa kajian terhadap permasalahan dan pengembangan yang akan dilakukan dalam web yaitu:

a. Penentuan tujuan, sasaran pengembangan dan konfigurasinya.

b. Teknologi yang digunakan

c. Penentuan kebutuhan informasi

d. Asal dan informasi yang disajikan

\section{Analisis kebutuhan}

Pada tahap ini dilakukan analisis kebutuhan sistem yang meliputi:

a. Output yang diinginkan

Output yang diinginkan dari web-based computer assisted design untuk dimensi bangunan pelengkap irigasi di tinjau dari pengguna sistem yaitu pengguna akan mendapatkan informasi mengenai perhitungan dimensi bangunan goronggorong dan talang, yang akan memudahkan dalam perencanaan dan perancangan bangunan pelengkap irigasi.

b. Data yang dibutuhkan

Data yang dibutuhkan yaitu data debit rencana, kecepatan aliran, koefisien kekasaran Strickler, kehilangan tinggi energi dan kemiringan. 
c. Perencanaan hidrolis

Pada perencanaan hidrolis dilakukan penentuan dimensi bangunan dilakukan dengan tahapan berikut :

1. Bangunan gorong-gorong

Penentuan dimensi bangunan goronggorong antara lain :

a) Kecepatan aliran

Rumus kecepatan aliran yang digunakan pada penentuan dimensi gorong-gorong adalah :

$$
\begin{gathered}
V=\frac{Q}{A} \\
V=\sqrt{2 \cdot g \cdot Z} \\
V=K R^{2 / 3} S^{1 / 2}
\end{gathered}
$$

Keterangan:

$\mathrm{V}=$ kecepatan aliran $(\mathrm{m} / \mathrm{s})$

$\mathrm{Q}=$ Debit rencana $\left(\mathrm{m}^{3} / \mathrm{s}\right)$

$\mathrm{g}=$ Percepatan gravitasi $\left(\mathrm{m} / \mathrm{s}^{2}\right)$

$\mathrm{z}=$ kehilangan tinggi energi pada gorong- gorong $(\mathrm{m})$

$\mathrm{K}=$ koefisien kekasaran

$\mathrm{R}=$ Jari-jari hidraulik (m)

$\mathrm{S}=$ Kemiringan dasar saluran

b) Kehilangan tinggi energi

kehilangan tinggi energi untuk gorong-gorong pendek $(1<20 \mathrm{~m})$ yang mengalir penuh dapat diketahui dengan rumus :

Keterangan :

$$
Q=\mu \cdot A \cdot \sqrt{2 \cdot g \cdot Z}
$$

$\mathrm{Q}=$ Debit rencana $\left(\mathrm{m}^{3} / \mathrm{s}\right)$

$\mu=$ Koefisien debit

$\mathrm{A}=$ Luas penampang $\left(\mathrm{m}^{2}\right)$

$\mathrm{g}=$ Percepatan gravitasi $\left(\mathrm{m} / \mathrm{s}^{2}\right)$

$\mathrm{z}=$ Kehilangan energi pada gorong-gorong.

c) Keliling basah

Untuk perhitungan keliling basah pada gorong-gorong dapat digunakan rumus sebagai berikut :

$$
P=2(b+h)
$$

Keterangan:

$\mathrm{P}=$ keliling basah $(\mathrm{m})$

$\mathrm{b}=$ lebar saluran $(\mathrm{m})$

$\mathrm{h}=$ kedalaman saluran tergenang air (m) d) Jari-jari hidrolis

Untuk perhitungan jari-jari hidrolis pada gorong-gorong dapat digunakan rumus :

$$
R=\frac{A}{P}
$$

Keterangan:

$\mathrm{R}=$ Jari-jari hidrolis $(\mathrm{m})$

$A=$ Luas penampang $(\mathrm{m} 2)$

$\mathrm{P}=$ Keliling basah $(\mathrm{m})$

e) Luas penampang

Untuk mengetahui luas penampang pada gorong-gorong digunakan rumus:

$$
A=b \times h
$$

Keterangan:

$\mathrm{A}=$ Luas penampang $(\mathrm{m} 2)$

$\mathrm{b}=$ Lebar saluran $(\mathrm{m})$

$\mathrm{h}=$ Kedalaman saluran dalam yang tergenang air $(\mathrm{m})$

2. Bangunan talang

Penentuan dimensi bangunan talang antara lain :

a) Kecepatan aliran

Rumus kecepatan aliran yang digunakan pada penentuan dimensi talang adalah :

Keterangan :

$$
V=\frac{Q}{A}
$$

$\mathrm{V}=$ Kecepatan aliran $(\mathrm{m} / \mathrm{s})$

$\mathrm{Q}=$ Debit rencana $\left(\mathrm{m}^{3} / \mathrm{s}\right)$

$\mathrm{A}=$ Luas penampang $\left(\mathrm{m}^{2}\right)$

b) Keliling basah

Untuk perhitungan keliling basah pada talang dapat digunakan rumus sebagai berikut :

$$
P=b+h(b+m \cdot h)
$$

Keterangan :

$\mathrm{P}=$ Keliling basah $(\mathrm{m})$

$\mathrm{b}=$ Lebar saluran $(\mathrm{m})$

$\mathrm{h}=$ Kedalaman saluran yang tergenang air $(\mathrm{m})$

$\mathrm{m}=$ Kemiringan talud

c) Jari-jari hidrolis

Untuk perhitungan jari-jari hidrolis pada talang dapat digunakan rumus:

$$
R=\frac{A}{P}
$$


Keterangan :

$\mathrm{R}=$ Jari-jari hidrolis $(\mathrm{m})$

$\mathrm{A}=$ Luas penampang $(\mathrm{m} 2)$

$\mathrm{P}=$ Keliling basah $(\mathrm{m})$

d) Luas penampang

Untuk mengetahui luas penampang pada talang digunakan rumus :

$$
A=h(b+m \cdot h)
$$

Keterangan:

$$
\begin{aligned}
& \mathrm{A}=\text { Luas penampang }\left(\mathrm{m}^{2}\right) \\
& \mathrm{b}=\text { Lebar saluran }(\mathrm{m}) \\
& \mathrm{m}=\operatorname{Kemiringan} \text { talud }(\mathrm{m}) \\
& \mathrm{h}=\operatorname{Kedalaman} \text { saluran }(\mathrm{m})
\end{aligned}
$$

\section{Pengembangan web}

Pada pengembangan web dilakukan bebrapa tahapan sebagai berikut:

a. Menyediakan perangkat lunak yaitu visual studio untuk menjalankan bahasa pemograman HTML dan javascript.

b. Membuat Script

scripts atau bahasa program yang digunakan untuk menerjemahkan setiap perintah dalam situs yang pada saat di akses.

c. Perancangan algoritma

Untuk mempermudah dalam pembuatan bahasa program maka terlebih dahulu di buat algoritma dari rumus kecepatan aliran, debit saluran, jari-jari hidrolis, keliling basah setiap bangunan.

d. Membuat Fungsi

Fungsi (function) merupakan serangkaian script atau kode yang mempunyai kegunaan khusus dan terte ntu merupakan seurutan atau serangkaian kode yang sering dipakai.

e. Content dan design

Content merupakan informasi yang ditampilkan pada website yang berupa teks atau gambar tentang dimensi bangunan gorong-gorong dan sipon sedangkan design merupakan tampilan website yang berfungsi untuk memperindah tampilan. Pada tahapan Content dan design di buat rancangan program dan desain tampilan website terlebih dahulu, kemudian dibuatkan program. Rancangan ini meliputi pembuatan algoritma rumus, pembuatan bahasa program dan rencana tampilan.
Tampilan web di buat dengan struktur navigasi model hierarki yaitu di mulai dari satu node yang menjadi homepage. Dari home page dapat di buat berupa beberapa cabang ke halaman-halaman utama. Apabila diperlukan, dari tiap halaman utama dapat di kembangkan menjadi beberapa cabang lagi.

\section{Implementasi}

Impelementasi yang dimaksud merupakan proses pembuatan program yang berdasarkan pada desain sistem yang telah ditentukan. Pada tahapan ini dilakukan pengujian terhadap program pada web server sehingga program dapat dipastikan berjalan sesuai dengan apa yang direncanakan.

Selanjutnya web di uji pada beberapa server internet agar memungkinkan untuk pengguna mengakses informasi tersebut melalui internet (mozilla firefox dan chrome). Pada bab ini akan membahas mengenai hasil dan pengujian web-based computer assisted design pada bangunan pelengkap irigasi yang telah diterapkan berdasarkan metode penelitian pada bab sebelumnya. Sistem ini digunakan untuk memudahkan pengguna website dalam menemukan informasi yang berkaitan dengan bangunan gorong-gorong dan bangunan talang secara online.

\section{HASIL DAN PEMBAHASAN}

\section{Gambaran Umum Aplikasi Program}

Website yang di buat bersifat statis dimana konten tidak dapat diperbaharui secara flexibel dan perlu melakukan code ulang. Data yang digunakan pada sistem ini bersumber dari pengguna website atau yang dikenal dengan data input, data input yang di gunakan dapat berupa data debit, kecepatan yang pada setiap bangunan berbeda.

Aplikasi program yang digunakan pada website ini yaitu menggunakan visual code sebagai text editor, serta bahasa program yang digunakan berupa html, css, dan javascript. 
Tabel 1. gambaran umum interkasi-interaksi yang terjadi di dalam sistem.

\begin{tabular}{|c|c|c|}
\hline No & Aksi & Hasil \\
\hline 1. & $\begin{array}{l}\text { Membuat alamat } \\
\text { domain }\end{array}$ & $\begin{array}{l}\text { Website dapat di } \\
\text { akses oleh pengguna } \\
\text { secara umum. }\end{array}$ \\
\hline 2. & $\begin{array}{l}\text { Website di buat } \\
\text { statis }\end{array}$ & $\begin{array}{l}\text { Konten tidak dapat } \\
\text { diperbaharui secara } \\
\text { flexibel }\end{array}$ \\
\hline 3. & $\begin{array}{l}\text { Dalam konten } \\
\text { terdapat beberapa } \\
\text { bagian }\end{array}$ & $\begin{array}{l}\text { Setiap konten } \\
\text { memiliki isi yang } \\
\text { berbeda }\end{array}$ \\
\hline 4. & $\begin{array}{l}\text { Di buat konten } \\
\text { kalkulator }\end{array}$ & $\begin{array}{l}\text { Pengguna dapat } \\
\text { menghitung dimensi } \\
\text { bangunan sipon dan } \\
\text { bangunan gorong- } \\
\text { gorong }\end{array}$ \\
\hline 5. & $\begin{array}{l}\text { Di buat konten } \\
\text { konversi }\end{array}$ & $\begin{array}{l}\text { Pengguna dapat } \\
\text { mengkonversi dari } \\
\text { satu jenis satuan ke } \\
\text { satuan lain }\end{array}$ \\
\hline 6. & $\begin{array}{l}\text { Di buat konten } \\
\text { referensi }\end{array}$ & $\begin{array}{l}\text { Pengguna dapat } \\
\text { menemukan informasi } \\
\text { umum terkait dengan } \\
\text { bangunan sipon dan } \\
\text { bangunan gorong- } \\
\text { gorong }\end{array}$ \\
\hline 7. & $\begin{array}{l}\text { Di buat konten } \\
\text { tentang }\end{array}$ & $\begin{array}{l}\text { Menampilkan data } \\
\text { pribadi pembuat } \\
\text { website }\end{array}$ \\
\hline
\end{tabular}

\section{Gambaran output program}

Output yang di hasilkan dari website yang di buat dapat di lihat pada struktur link website yaitu terdiri dari menu home, konversi, kalkulator, referensi, bantuan dan tentang. menu kalkulator yang terdiri dari dua bangunan yaitu bangunan talang irigasi dan bangunan gorong-gorong segi empat.

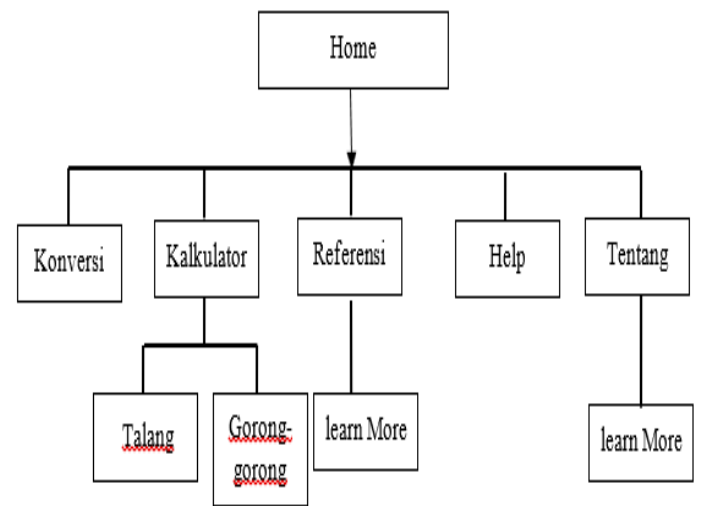

Gambar 1. Struktur link website

Menu kalkulator dapat digunakan untuk menentukan dimensi yang terdiri dari
A (luas penampang), $\mathrm{P}$ (keliling basah), $\mathrm{R}$ (jari-jari hidrolis), b (lebar saluran) dan $h$ (tinggi saluran) dengan input berdasarkan pada nilai $\mathrm{v}$ (kecepatan aliran) dan $\mathrm{Q}$ (debit rencana), input nilai kecepatan dan nilai debit rencana pada bangunan talang di dasar, data ini digunakan apabila tidak mempunyai data lapangan. Sedangkan input nilai debit rencana dan nilai $b$ dan $h$ pada bangunan gorong-gorong segi empat di dasarkan pada standar penulangan untuk gorong-gorong segi empat.

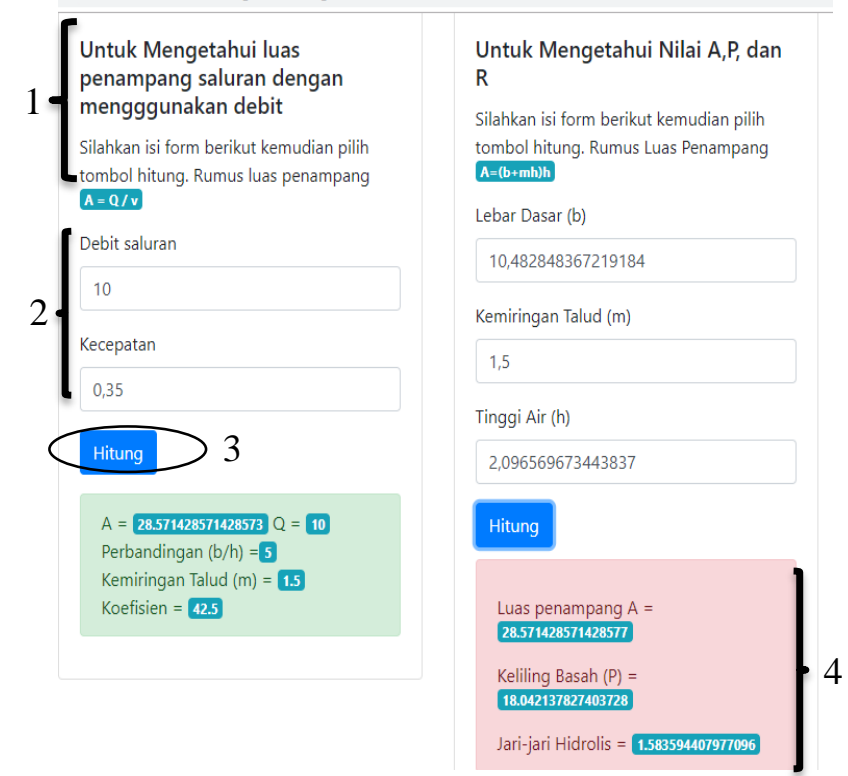

Gambar 2. Output menu kalkulator bangunan talang.

Pada menu kalkulator bangunan talang gambar 2 nomor 1 terdapat card body yang digunakan untuk menulis perintah yang akan di tujukan pada menu form yang ada di bawah dapat di lihat pada Gambar 2 nomor 2 apabila pengguna website menginput pada form nilai debit saluran (Q) dan nilai kecepatan aliran (v), maka secara otomatis akan muncul nilai A (luas penampang), nilai P (keliling basah), nilai R (jari-jari hidrolis), nilai b ( lebar saluran) dan nilai h (ketinggian saluran) (Gambar 2 nomor 4) setelah mengklik tombol hitung (Gambar 2 nomor $3)$. 


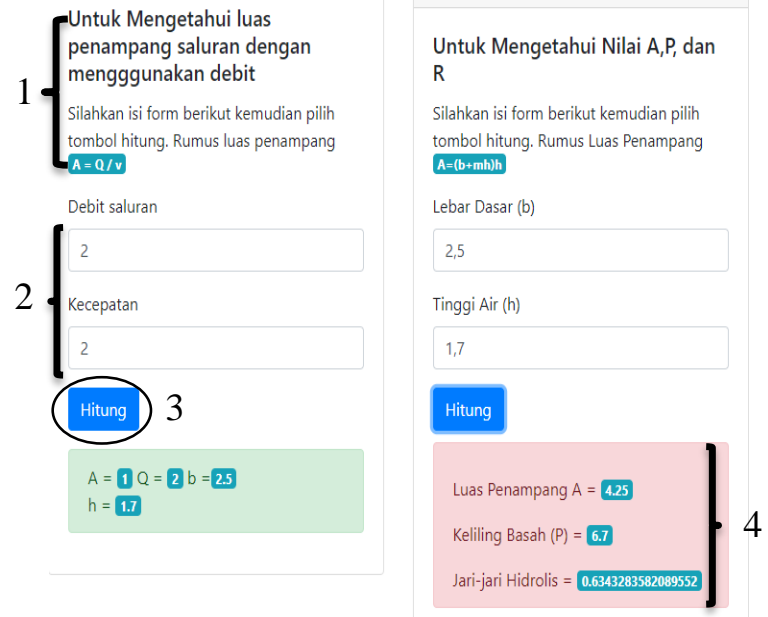

Gambar 3. Output menu kalkulator bangunan gorong-gorong segi empat

Pada menu kalkulator bangunan gorong-gorong segi empat dapat di lihat pada Gambar 3 nomor 1 terdapat card body yang digunakan untuk menulis perintah yang akan di tujukan pada menu form yang ada di bawah dapat di lihat pada Gambar 3 nomor 2 apabila pengguna website menginput pada form nilai debit saluran (Q) dan nilai kecepatan aliran (v), maka secara otomatis akan muncul nilai $b$ ( lebar saluran) dan nilai h ( ketinggian saluran). Pada Gambar 3 nomor 4 akan ditampilkan nilai A (luas penampang), nilai $\mathrm{P}$ (keliling basah), nilai $\mathrm{R}$ (jari-jari hidrolis) setelah mengklik tombol hitung (Gambar 3 nomor 3).
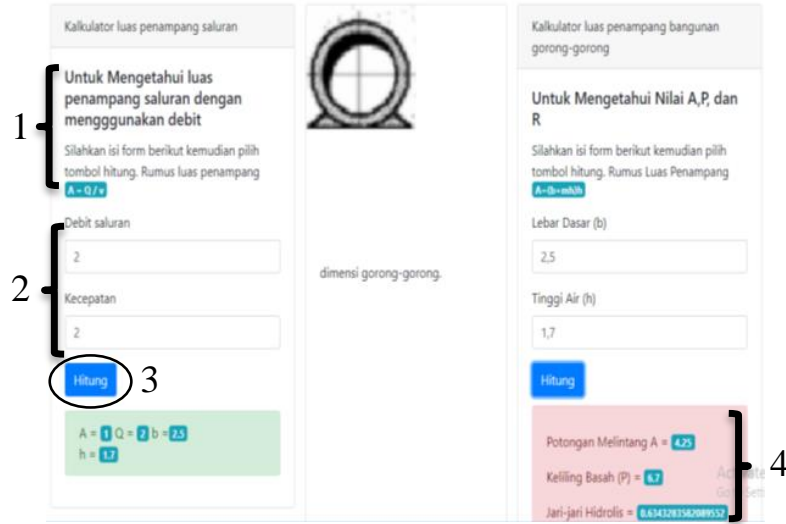

Gambar 4. Output menu kalkulator bangunan gorong-gorong bulat.

Pada menu kalkulator bangunan gorong-gorong bulat dapat di lihat pada Gambar 4 nomor 1 terdapat card body yang digunakan untuk menulis perintah yang akan di tujukan pada menu form yang ada di bawah dapat di lihat pada Gambar 4 nomor 2 apabila pengguna website menginput pada form nilai debit saluran (Q) dan nilai kecepatan aliran (v), maka secara otomatis akan muncul nilai b ( lebar saluran) dan nilai h ( ketinggian saluran). Pada Gambar 4 nomor 4 akan ditampilkan nilai A (luas penampang), nilai $\mathrm{P}$ (keliling basah), nilai $\mathrm{R}$ (jari-jari hidrolis) setelah mengklik tombol hitung (Gambar 4 nomor 3).

\section{Bahasa program}

Bahasa program yang digunakan pada pembuatan website ini yaitu menggunakan HTML dan java scrift, HTML di gunakan pada bagian desain halaman web yang terdiri dari menu dan navigasi bar. Hal ini sesuai dengan pendapat (Swastikayana, 2011) yang menyatakan bahwa HTML adalah slah satu format yang digunakan untuk menulis halaman web.

Java script di gunakan khusus pada perhitungan matematika seperti pada menu kalkulator bangunan talang dan menu kalkulator gorong-gorong segi empat serta menu konversi. Penggunaan java script pada bahasa program di tandai dengan adanya fungsi math yang membedakan dengan bahasa PHP. Contoh penggunaan bahasa program HTML dapat dilihat pada lampiran script menu halaman utama, menu konversi, menu referensi, menu bantuan, dan menu tentang. Sedangkan contoh penggunaan bahasa program java script dapat di lihat pada lampiran script perhitungan kalkulator bangunan talang dan bangunan goronggorong segi empat.

\section{Pengujian Sistem}

Pada tahap pengujian website dilakukan penginputan terhadap beberapa sampel data. Hal ini dilakukan untuk melihat respon website telah bekerja sesuai atau tidak sesuai dengan yang di rencanakan, apabila respon website telah sesuai maka dapat di katakan bahwa website layak untuk digunakan.

Hasil pengujian pada website ini dapat di lihat pada Tabel hasil pengujian fungsional berikut: 
Tabel 2. Pengujian fungsional website

\begin{tabular}{|c|c|c|c|}
\hline No & $\begin{array}{c}\text { Skenario } \\
\text { Pengujian }\end{array}$ & $\begin{array}{l}\text { Hasil yang } \\
\text { diharapkan }\end{array}$ & Hasil \\
\hline 1. & $\begin{array}{l}\text { Mengakses } \\
\text { halaman }\end{array}$ & $\begin{array}{l}\text { Masuk ke halaman } \\
\text { awal website }\end{array}$ & $\sqrt{ }$ \\
\hline 2. & $\begin{array}{l}\text { Membuka } \\
\text { halaman } \\
\text { utama } \\
\text { website }\end{array}$ & $\begin{array}{l}\text { Menampilkan } \\
\text { tampilan pembuka } \\
\text { dari website }\end{array}$ & $\sqrt{ }$ \\
\hline 3. & $\begin{array}{l}\text { Membuka } \\
\text { menu } \\
\text { kalkulator }\end{array}$ & $\begin{array}{l}\text { Menampilkan } \\
\text { desain kalkulator } \\
\text { dari dua bangunan } \\
\text { yaitu bangunan } \\
\text { talang, sipon, dan } \\
\text { gorong-gorong }\end{array}$ & $\sqrt{ }$ \\
\hline 4. & $\begin{array}{l}\text { Mengisi } \\
\text { form yang } \\
\text { ada pada } \\
\text { menu } \\
\text { kalkulator }\end{array}$ & $\begin{array}{l}\text { Menampilkan hasil } \\
\text { perhitungan yang di } \\
\text { isi pada form } \\
\text { dengan meng klik } \\
\text { hitung }\end{array}$ & $\sqrt{ }$ \\
\hline 5. & $\begin{array}{l}\text { Membuka } \\
\text { menu } \\
\text { konversi }\end{array}$ & $\begin{array}{l}\text { Menampilkan hasil } \\
\text { konversi dari satu } \\
\text { jenis satuan ke } \\
\text { satuan lainnya }\end{array}$ & $\sqrt{ }$ \\
\hline 6. & $\begin{array}{l}\text { Membuka } \\
\text { menu } \\
\text { referensi }\end{array}$ & $\begin{array}{l}\text { Menampilkan } \\
\text { informasi tentang } \\
\text { bangunan } \\
\text { pelengkap }\end{array}$ & $\sqrt{ }$ \\
\hline 7. & $\begin{array}{l}\text { Mebuka } \\
\text { menu } \\
\text { bantuan }\end{array}$ & $\begin{array}{l}\text { Menampilkan } \\
\text { langkah } \\
\text { penggunaan } \\
\text { website }\end{array}$ & $\sqrt{ }$ \\
\hline 8. & $\begin{array}{l}\text { Membuka } \\
\text { menu } \\
\text { tentang }\end{array}$ & $\begin{array}{l}\text { Menampilkan } \\
\text { biografi pembuat } \\
\text { website }\end{array}$ & $\sqrt{ }$ \\
\hline
\end{tabular}

\section{Implementasi sistem pada server}

Program dapat di uji coba pada web server yang dapat di akses sementara melalui www.unhas.ac.id untuk pengguna, sistem ini dapat di akses oleh masyarakat umum akan tetapi sistem ini bersifat statis yakni apabila ada perubahan terhadap data maka di lakukan code ulang. Sistem ini terdiri dari beberapa menu antara lain:

\section{Halaman utama}

Website akan di upload di www.unhas.ac.id. Dengan mengakses www.unhas.ac.id maka pengguna akan di arahkan ke halaman utama website yang menjelaskan secara umum apa yang terdapat pada website, tampilannya dapa di lihat pada gambar berikut ini:

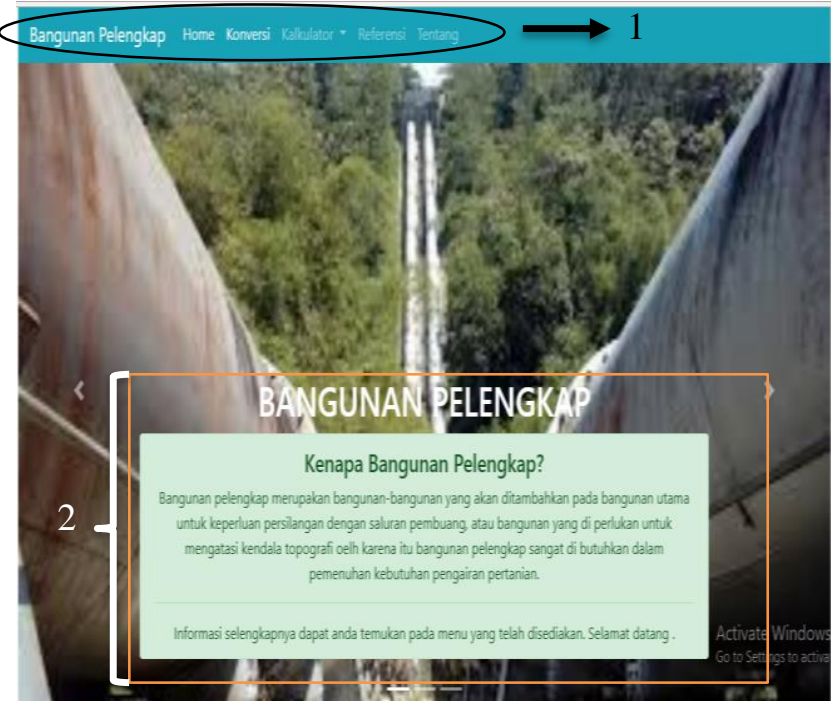

Gambar 5. Halaman utama website

Pada halaman awal, publik dapat melihat tampilan navigasi bar dapat di lihat pada Gambar 5 nomor 1 yang berisi beberapa menu yaitu menu home, menu konversi, menu kalkulator, menu referensi, menu bantuan, dan menu tentang. yang terdapat dalam website assisted pada bangunan pelengkap irigasi untuk melihat isi dari setiap menu publik dapat mengklik judul menu yang ingin di buka.

Selain navigasi bar juga terdapat tulisan dan gambar salah satu bangunan pelengkap (Gambar 5 nomor 2), dengan adanya tampilan awal ini membuat pengguna terarah dan dapat memahami isi dari website yang di buat. Seperti yang di jelaskan pada bab sebelumnya jenis website yang di rancang fokus pada bangunan pelengkap irigasi untuk beberapa menu, bangunan pelengkap terdiri dari bangunan sipon, bangunan gorong-gorong, bangunan terjun, bangunan talang, dan bangunan flum. Namun tidak semua jenis bangunan pelengkap ini di bahas dalam menu kalkulator meskipun pada menu lain semua jenis bangunan pelengkap di bahas dikarenakan pada menu kalkulator hanya membahas bangunan talang dan goronggorong.

\section{Menu konversi}

Menu konversi di buat agar pengguna website dapat mengkonversi dari satu jenis satuan ke satuan lainnya (gambar 7 nomor 2) tanpa harus keluar dari halaman website. 
Ada beberapa satuan yang berkaitan dengan dimensi bangunan seperti satuan Panjang, massa, dan lain-lain. Pada bagian ini daplikasikan menu drop down, sehingga pengguna dapat memilih dengan mudah jenis satuan yang akan di konversi dengan cara drop maupun down (Gambar 6 nomor 1). Setelah menentukan jenis satuan yang akan digunakan pengguna dapat menginput nilai pada kotak bagian atas pada Gambar 6 nomor 3 maka akan muncul hasil hitung pada kotak bagian bawah (Gambar 6 nomor 3 ) setelah mengklik tombol hitung (Gambar 6 nomor 4$)$.

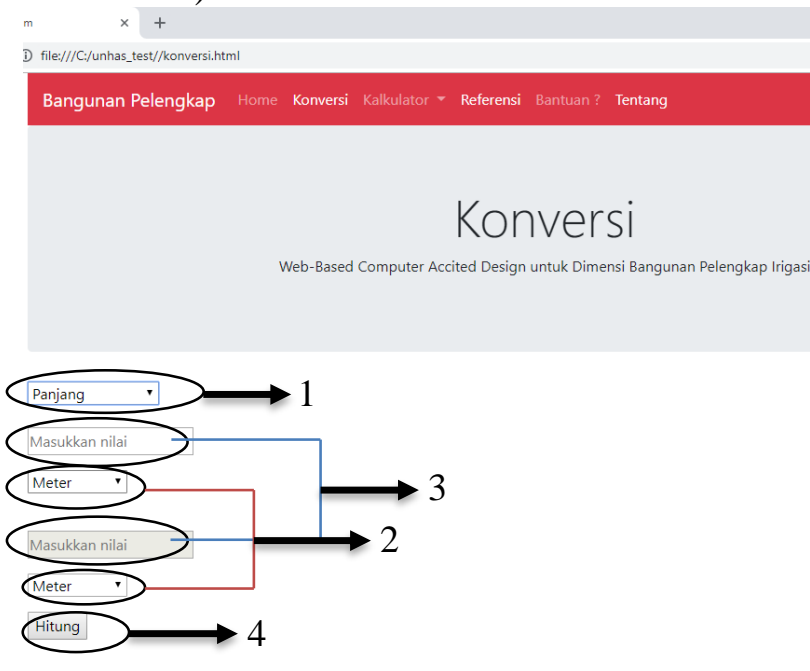

Gambar 6. Menu konversi

\section{Menu kalkulator}

Pada menu kalkulator terdapat dua jenis bangunan yang dapat di hitung dimensinya yaitu bangunan gorong-gorong dan banguna talang. Namun pada dasarnya bangunan pelengkap tidak hanya terdiri dari dua jenis bangunan (bangunan sipon dan gorong-gorong) masih ada jenis bangunan lain misalnya bangunan talang, flum dan bangunan terjun dapat di lihat pada menu lain yang ada di navigasi bar.

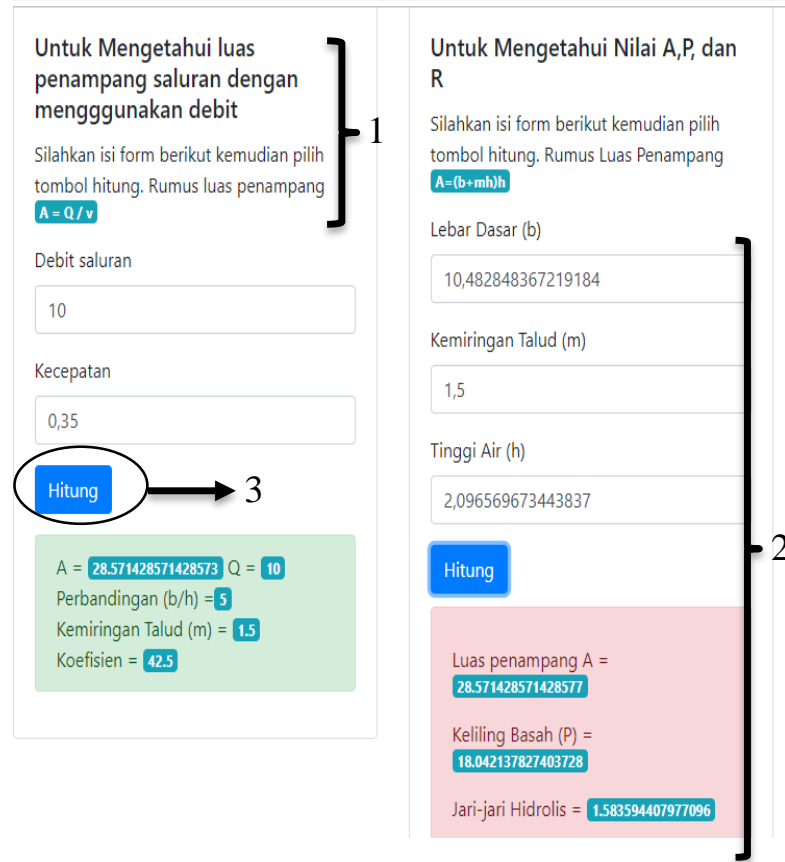

Gambar 7. Menu kalkulator pada bangunan talang.

Pada bangunan talang dimensi yang dapat di hitung terdiri dari dimensi luas (A), keliling basah $(\mathrm{P})$ dan jari-jari hidrolis $(\mathrm{R})$, kemiringan talud, kecepatan maksimum, nilai b (lebar saluran), nilai h (tinggi saluran) dan nilai koefisien dapat di lihat pada Gambar 7 nomor 2, dengan data input berupa debit, nilai. Apabila data yang di input maka setealah mengklik tombol hitung (Gambar 7 nomor 3) akan menghasilkan unknown atau tidak terdeteksi.

Pada bangunan gorong-gorong segi empat dimensi yang dapat di hitung terdiri dari dimensi luas (A), keliling basah (P) dan jari-jari hidrolis (R) dapat di lihat pada Gambar 8 nomor 4 dengan data input berupa debit (Q), nilai b (lebar saluran) pada Gambar 8 nomor 3. Apabila data yang di input salah maka setelah mengklik tombol hitung pada Gambar 8 nomor 1 akan menghasilkan unknown atau tidak terdeteksi. 


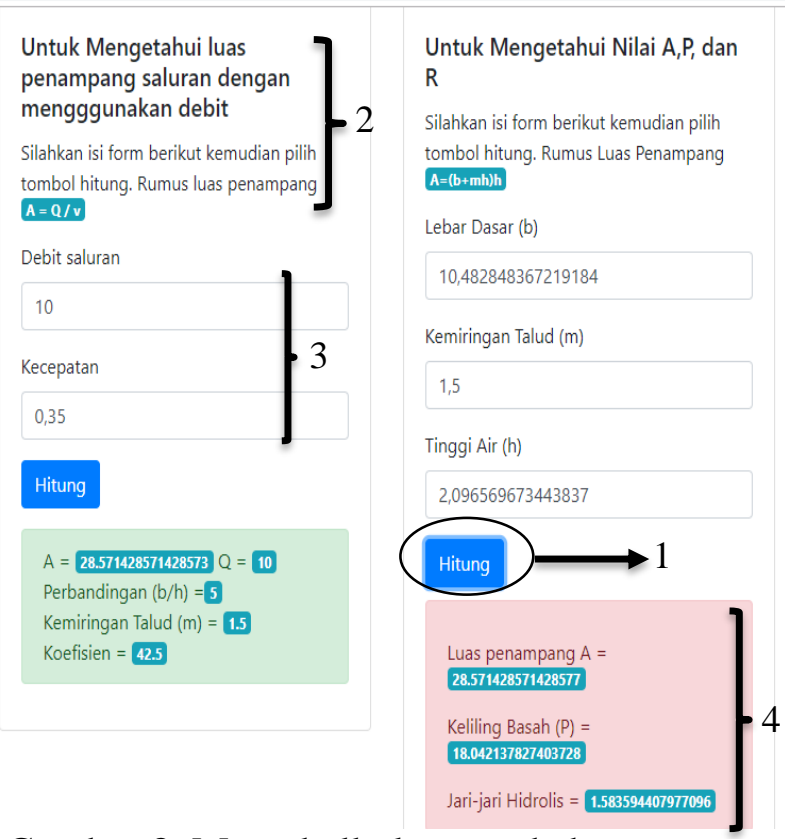

Gambar 8. Menu kalkulator pada bangunan gorong-gorong segi empat.

Pada bangunan gorong-gorong bulat dimensi yang dapat di hitung terdiri dari dimensi luas (A), keliling basah (P) dan jarijari hidrolis (R) dapat di lihat pada Gambar 9 nomor 4 dengan data input berupa debit (Q), nilai b (lebar saluran) pada Gambar 9 nomor 3. Apabila data yang di input salah maka setelah mengklik tombol hitung pada Gambar 9 nomor 1 akan menghasilkan unknown atau tidak terdeteksi.
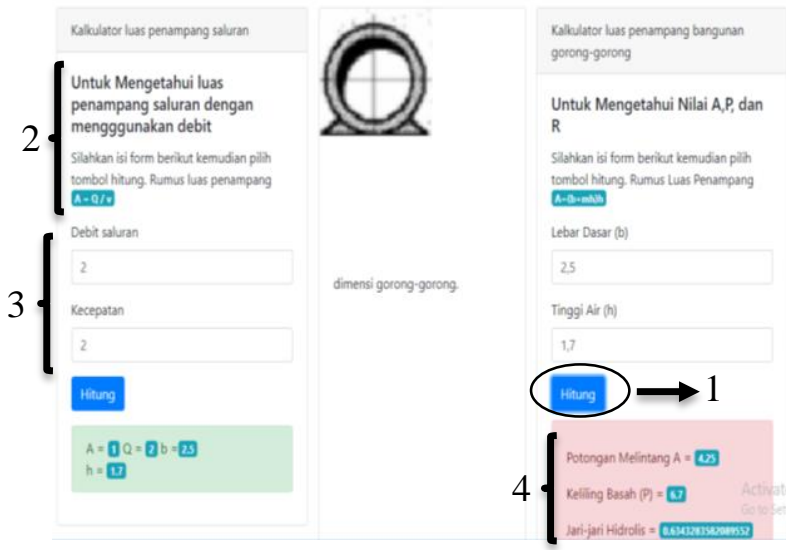

Gambar 9. Menu kalkulator pada bangunan gorong-gorong bulat

\section{Menu Referensi}

Menu referensi merupakan menu yang berisi tentang informasi bangunan pelengkap yaitu bangunan gorong-gorong, bangunan sipon, bangunan talang, bangunan flum dan banguna terjun lihat pada Gambar 10. Menu ini dapat di akses untuk mengetahui pengertian, tujuan, serta bentuk dari beberapa jenis bangunan pelengkap, seperti halnya bangunan gorong-gorong di buat untuk mengalirkan air di bawah jalan raya, kereta api dan lain-lain informasi seperti ini dapat di peroleh pengguna pada bagian menu referensi seperti pada gambar di bawah:

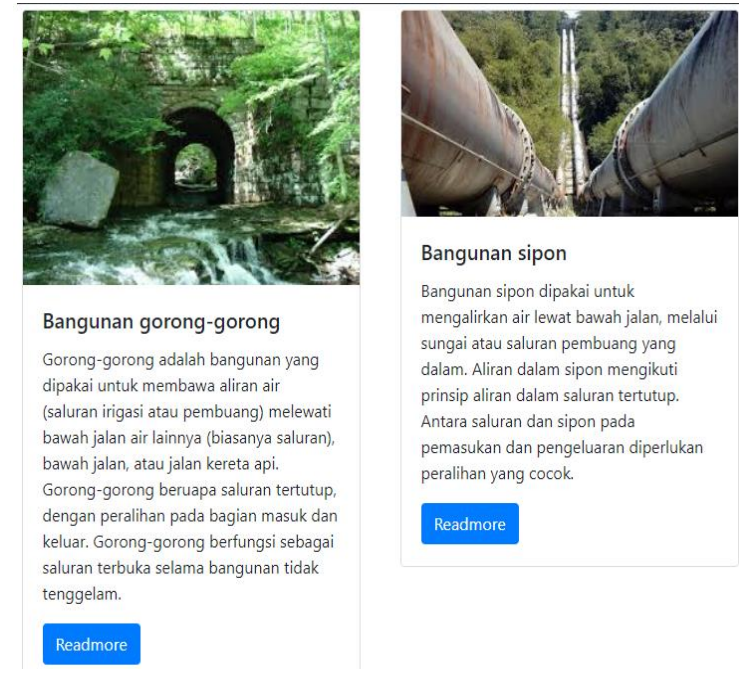

Gambar 10. Menu referensi

5. Menu bantuan

Menu bantuan atau dikenal dengan petunjuk berisi tentang bagaiamana cara mengaplikasin website ini, pada menu ini dijelaskan beberapa menu dan juga langkahlangkah penggunaan website agar pengguna website tidak mengalami kesulitan dalam penggunaannya dapat dilihat pada Gambar 11.

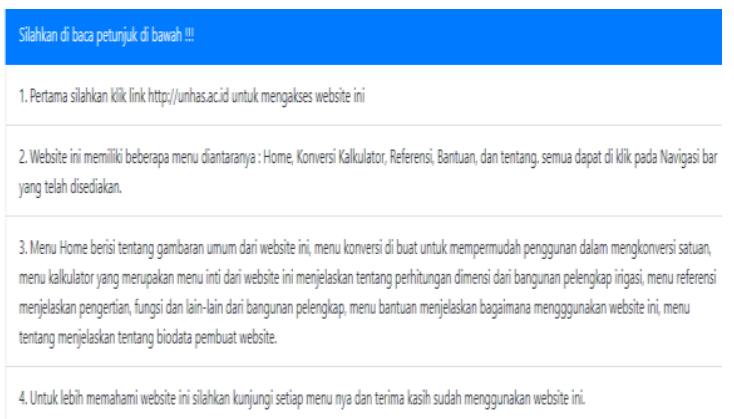

Gambar 11. Menu bantuan

\section{Menu Tentang}

Menu tentang berisi tentang informasi pribadi dari pembuat website dapat di lihat pada Gambar 12 nomor 1, untuk informasi 
selanjutnya mengenai penulis pengguna dapat mengklik learn more yang ada pada bagian bawah lihat Gambar 12 nomor 2 .
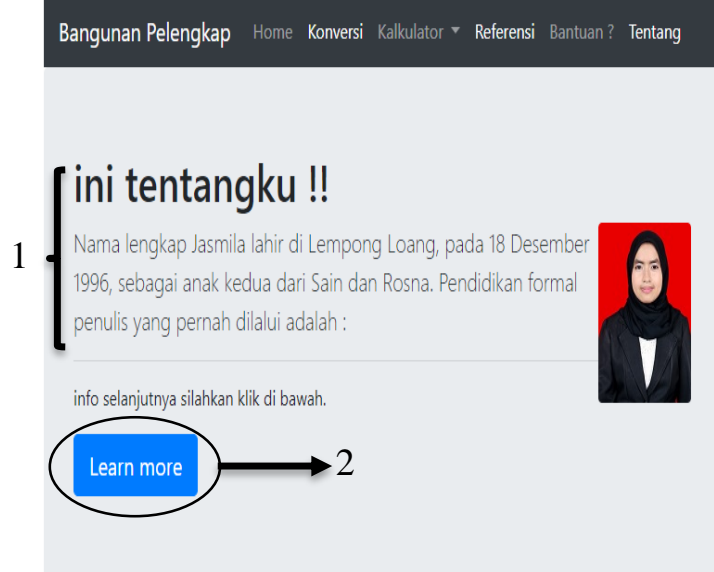

Gambar 12. Menu biodata

\section{KESIMPULAN}

Berdasarkan penelitian yang telah dilakukan, maka dapat disimpulkan bahwa:

1. Web based computer assisted design untuk penentuan dimensi bangunan pelengkap irigasi telah di unggah dan dapat digunakan untuk perhitungan dimensi bangunan talang dan goronggorong.

2. Dengan web based computer assisted design para perancang dapat dengan mudah melakukan perhitungan dimensi bangunan gorong-gorong dan talang.

\section{DAFTAR PUSTAKA}

Direktorat Jendral Pengairan.2013.Kriteria Perencanaan Jaringan Irigasi KP-04, Kriteria Perencanaan Bagian Bangunan. Departemen PU Galang Persada. Bandung

Direktorat Jendral Pengairan.2010.Kriteria Perencanaan Jaringan Irigasi KP-O1, Kriteria Perencanaan Bagian Perencanaan Jaringan Irigasi. Departemen PU Galang Persada. Bandung.

Hadihardjaja, Joetata. 1997. Irigasi dan Bangunan Air. Universitas Gunadarma. Jakarta.
Swastikayana, I Wayan Eka. 2011. Sistem Informasi Geografis Berbasis Web Untuk Pemetaan Pariwasata Kabupaten Gianyar. Yogyakarta

Wicaksono, Panji P. 2014. Perencanaan Bangunan Pelimpah Pada Embung Di Perkebunan Bungamayang PT. Perkebunan Nusantara VII. Institut Pertanian Bogor. Jawa Barat 